\title{
ALBEDO PATTERN RECOGNITION AND TIME-SERIES ANALYSES IN MALAYSIA
}

\author{
S. A. Salleh ${ }^{\text {a }}$ Z. Abd Latif ${ }^{\text {a, } * \text { W. M. N. Wan Mohd }}{ }^{\text {a }}$, A. Chan ${ }^{\text {b }}$ \\ ${ }^{a}$ Center for Surveying Science and Geomatics Studies, Faculty of Architecture Planning and Surveying, \\ Universiti Teknologi MARA (UiTM), 40450 Shah Alam, Selangor, Malaysia. \\ ${ }^{\mathrm{b}}$ Faculty of Engineering, University of Nottingham, Campus Semenyih, Jalan Broga, Selangor, Malaysia \\ zulki721@salam.uitm.edu.my
}

Commission VII, WG VII/4

KEY WORDS: Environment, Temporal, Pattern, Spatial, Meteorology, Climate

\begin{abstract}
:
Pattern recognition and time-series analyses will enable one to evaluate and generate predictions of specific phenomena. The albedo pattern and time-series analyses are very much useful especially in relation to climate condition monitoring. This study is conducted to seek for Malaysia albedo pattern changes. The pattern recognition and changes will be useful for variety of environmental and climate monitoring researches such as carbon budgeting and aerosol mapping. The 10 years (2000-2009) MODIS satellite images were used for the analyses and interpretation. These images were being processed using ERDAS Imagine remote sensing software, ArcGIS 9.3, the 6S code for atmospherical calibration and several MODIS tools (MRT, HDF2GIS, Albedo tools). There are several methods for time-series analyses were explored, this paper demonstrates trends and seasonal time-series analyses using converted HDF format MODIS MCD43A3 albedo land product. The results revealed significance changes of albedo percentages over the past 10 years and the pattern with regards to Malaysia's nebulosity index (NI) and aerosol optical depth (AOD). There is noticeable trend can be identified with regards to its maximum and minimum value of the albedo. The rise and fall of the line graph show a similar trend with regards to its daily observation. The different can be identified in term of the value or percentage of rises and falls of albedo. Thus, it can be concludes that the temporal behavior of land surface albedo in Malaysia have a uniform behaviours and effects with regards to the local monsoons. However, although the average albedo shows linear trend with nebulosity index, the pattern changes of albedo with respects to the nebulosity index indicates that there are external factors that implicates the albedo values, as the sky conditions and its diffusion plotted does not have uniform trend over the years, especially when the trend of 5 years interval is examined, 2000 shows high negative linear trend relationship $\left(R^{2}=0.8017\right)$, while in 2005 the $R^{2}$ is 0.4428 of positive linear trend relationship and in 2009 its negative relationship has remarkably change when the $\mathrm{R}^{2}$ is 0.9663 according to the second order polynomial trend line.
\end{abstract}

\section{INTRODUCTION}

\subsection{Albedo Pattern for Environmental and Climate Condition}

The study of land surface albedo and its inter-dependences towards global climate condition have been conducted by several researchers i.e (Zhou et al. 2003), (Akbari et al. 2009), (Govaerts and Lattanzio 2008) and (Ollinger et al. 2008). Liu, Schaaf et al. (2009) quoted definition of albedo from Dickinson (1978) as "Land surface albedo is defined as the fraction of incident solar irradiance reflected by Earth's surface over the whole solar spectrum". It can simply be defined as the amount of incoming radiation that is reflected from the surface.

Land surface albedo plays a significant role in determining and controlling the energy budget. Researchers has been studying it properties through its dependency on solar zenith angle as to validate the source of image dataset (Liu et al. 2009a), the correlation of radiative forcing and landuse (Kvalevåg 2009; Kvalevåg et al. 2010; Nair et al. 2007) and improvement or downscaling its data spatial resolution to enable higher accuracy and more details results for study involving microclimate condition (Liu et al. 2009b; Liu et al. 2007; M ttus and Rautiainen 2009; Nasipuri et al. 2006; Rocchini 2007).
Remote sensing and GIS technology certainly give advantages to allow bigger coverage data retrieval and huge data mining purposes. There are several studies in relation to albedo that have utilized these technologies. Satellite derived albedo such as Meteosat was used in several researches to seek for discrepancies through documenting the time-series data and analysis (Loew and Govaerts 2010), identification of spatial and temporal distribution of aerosol (Pinty et al. 2000), and drought events (Govaerts and Lattanzio 2008). (Pinty et al. 2000) used 10 years of Meteosat datasets and has underlined the opportunity to document the changes and subsequently enable one to monitor land surface dynamics.

Landsat image was also being used for monitoring earth albedo and study of vegetation indices relationship with surface roughness (Kiang and Ungar 1977; Yunjun et al. 2008). While Moderate Resolution Imaging Spectroradiometer (MODIS) have been through numerous verification and validation studies (Liu et al. 2009a; Lucht et al. 2000; Stroeve et al. 2005), AVHRR and GOES was used to retrieve red spectral albedo and bidirectional reflectance (d'Entremont et al. 1999). A comprehensive datasets with viable temporal resolution where the data is being observed in a sequence of time enable a domain of statistical analyses known as time-series analysis.

\footnotetext{
* Corresponding author.
} 
1.2 The Time Series Analyses: Significance and System Availability

Time-series analysis has been widely used in the area of global climate change. This type of analysis is categorized as environmental statistics (Smith, 1999). Dealing with time series data, there are several typical questions one might want to know such as identifying the time focus dependence of certain climate condition, recognizing pattern, forecasting phenomena, search or establish mitigation strategy based on identified parameters or variables and finally time series analysis is also the type of analysis that lead to other significance analysis based on the acclaimed correlations. As for Malaysia, our typical Monsoons (2 inter-monsoons and 2 main monsoons) can be the time focus dependence.

Climate change studies that involves time series analyses revolves in the issues of precipitation, and urban heat island (Cicek and Turkoglu 2005; Dixon and Mote 2010; Ghazanfari et al. 2009; Kishtawal et al. 2010). Recognition of pattern will enable hierarchical classification scheme over a large set of data. This recognition allowed researcher to perform predictive analyses. The bases of predictive results are usually based on spatial pattern, changes pattern, movement pattern etc.

The change in urban albedo has significant impact on the evolution of UHI, thus yielding a more reasonable intensity of UHI relative to the actually observed value. Ducham and Hamm (2006) plotted daily albedo with respect to the daily precipitation and NDVI and their time series analyses indicate that the dependency of albedo on precipitation is relatively high.

In due respect to the above information, being such an important element in our climate condition and realizing the importance of knowing its pattern in monitoring and mitigating strategies for adapting or securing our environment as it is mentioned in (Bala et al. 2007; Lawrence and Chase 2010) it is an urge to identify the albedo pattern changes of Malaysia. This finding will become handy to the local climate researcher in order to improvise or maybe calibrate any of the climate models available to suits Malaysia climate conditions.

\section{METHODS FOR DATA PROCESSING AND SPATIAL DATA REPRODUCTION}

\subsection{Study Area}

MODIS land surface product MCD43A3 at horizontal tile 38 and vertical tile 08 is downloaded via Land Process Distributed Active Archived Center (LPDAAC) website. These images were been processed every 8 daily sinusoidal at $500 \mathrm{~m}$ spatial resolution. The grid covers west part of Malaysia which also known as Peninsular Malaysia. Its area is 131,598 square kilometers $(50,810$ square miles). It shares a land border with Thailand in the north (Figure 1).

Malaysia is one of the countries classified as tropical climate where hot and humid are the common characters. The average air temperature ranges from $20^{\circ} \mathrm{C}-35^{\circ} \mathrm{C}$ and occasionally exceeded $35^{\circ} \mathrm{C}$ depending on the variation of Monsoons. The Peninsular Malaysia experiencing quite a remarkable monsoon variation. Notably along the coastline area where and extreme events of rainfall and flood can be expected during specific monsoon.

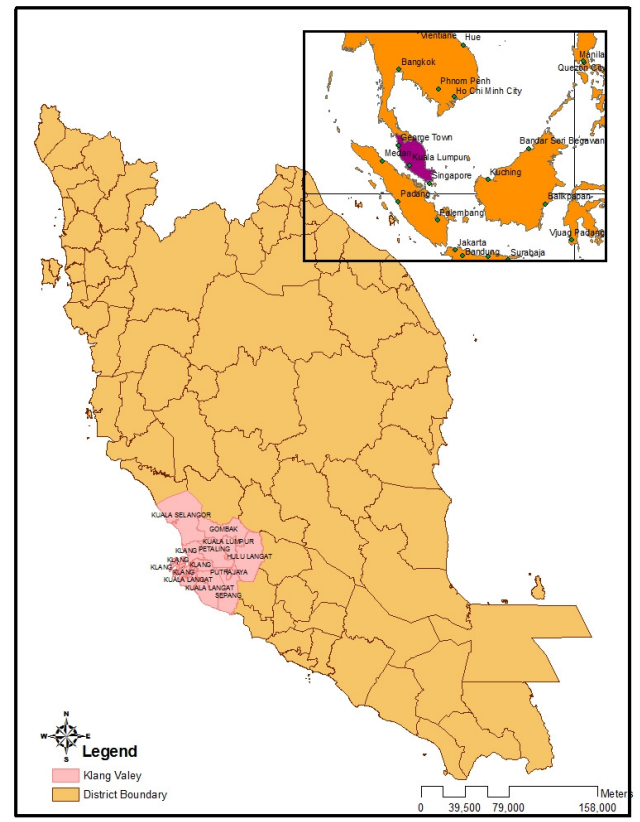

Figure 1. The Peninsular Malaysia

\subsection{Data Retrieval and Acquisition}

The familiarization of MODIS data can simply be done through visiting the http://modis.gsfc.nasa.gov/index.php website. One has to be familiar with its spectral, spatial and temporal resolution. As each of its products have their very own specification. MODIS temporal resolution varies in term of what kind of information one wants to retrieve. For example, the land surface albedo product (MCD43A43) is available at sixteen daily coverages while the land cover data (MCD12Q1) is available yearly. Therefore, the specification recognition and familiarization is importance at the beginning in order to avoid mistakes in data acquisition process.

There are four experts software are used in this study. Two of them are commercially off the shelf scientific software known as ArcGIS 9.3 and ERDAS Imagine 9.1. ArcGIS 9.3 is used to process the spatial data and for mapping purposes. The spatial interpolation technique is conducted using this software. Erdas Imagine 9.1 mainly used for satellite image processing such as image density slicing, classification and conversion.

The other two tools are the $6 \mathrm{~S}$ code and the MRT Tools. The $6 \mathrm{~S}$ code is an application develops to simulate the solar radiation on the ground and in the atmosphere (Kotchenova and Vermote 2007; Kotchenova et al. 2006). The 6S stand for Second Simulation of a Satellite Signal in the Solar Spectrum is a basic code Radiative Transfer (RT) code. This code used for calculation of lookup tables in MODIS atmospheric correction algorithm (Justice et al. 2002; Vermote et al. 2002). This code is chose as it is not restricted to specific sensor, test site and object class which is very important when some parameters are impossible or difficult to obtain (Zhao et al. 2001).

The MRT Tools 4.0 was released in February 2008. It is a product in collaboration of Land Processes DAAC USGS Earth Resources Observation and Science (EROS) Center with the Department of Mathematics and Computer Science South Dakota School of Mines and Technology. This software is used 
for the MODIS land product image format conversion and coordinates transformation.

\subsection{Spatial Data Preparation and Analyses}

This study is conducted according to three major phases. The three major phases comprises of data dissemination, data reproduction and transformation and finally data analyses. Figure 2 illustrate the processes involved in retrieving albedo.

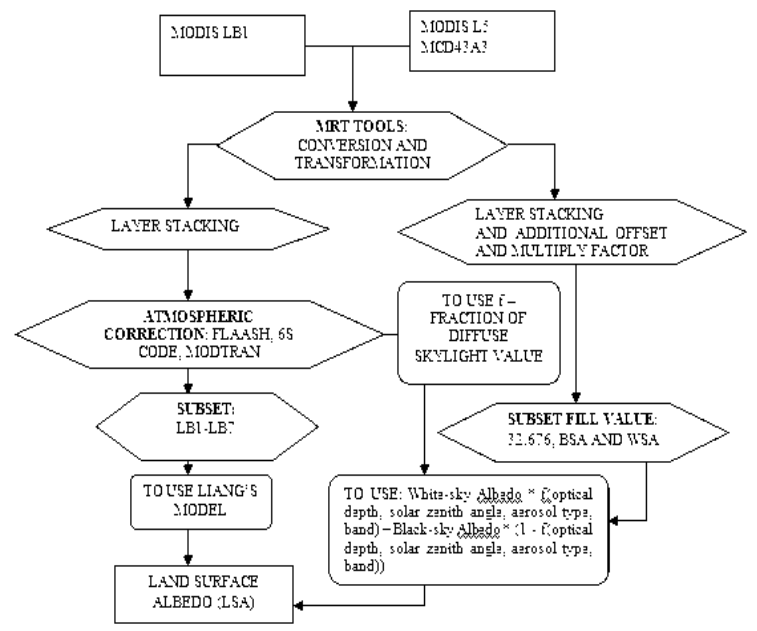

Figure 2. Albedo Retrieval Processes

The yearly and seasonal variations of land surface albedo for the study are is derived according to the following steps:

1. The MODIS data (MCD43A3) were projected into WGS84 and converted into GeoTIFF format and Binary format using the MRT tools.

2. The Black Sky Albedo (BSA) and White Sky Albedo (WSA) were then stacked into separate.

3. The fraction of diffuse skylight $(s)$ is identified using pre-determined lookup table and simulated beforehand using the $6 \mathrm{~S}$ code. The five parameters needed to perform the simulation are as follows (Wang et al. 2011; Zhao et al. 2001).

4. Geometrical Condition (value of solar zenith and azimuthal angle, satellite zenith and azimuthal angle and Julian Calendar of satellite revisit)

5. Atmospheric Model (tropical, mid latitude etc.) and Aerosol Model Type (LUT AOT550)

6. Ground and Sensor Altitude (0 represents ground surface and -1000 for sensor onboard satellite at outside atmosphere)

7. Spectral bands (MODIS 500m 7 Bands data is predefined in 6S Model)

8. Surface Reflectance Characteristics (homogeneous and non-uniform surface)

9. The statistical of multi-temporal surface albedo were calculated.

10. Visualization and Mapping

Based on BSA, WSA and the $s$ (fraction of diffuse skylight) determined in previous steps, the actual albedo can be calculated according to (Zhang et al. 2010).

$$
\rho=(1-s[\theta, \tau(\lambda)]) \rho \operatorname{dir}+s[\theta, \tau(\lambda)] \rho \operatorname{dif}
$$

where

$$
\begin{array}{ll}
\rho & =\text { the actual albedo } \\
s & =\text { the fraction of diffuse skylight } \\
\theta & =\text { Solar Zenith Angle }
\end{array}
$$

$$
\begin{aligned}
T & =\text { atmospheric optical depth } \\
\lambda & =\text { wavelength } \\
\rho d i r & =\text { the Black Sky Albedo } \\
\rho d i f & =\text { the White Sky Albedo }
\end{aligned}
$$

The $s$ value in this study is based on the Fresnel Reflectance coefficient light (Jerlov, 1976) which is set to 0.06 (Ambarwulan, 2010). The designs of analyses are based on daily, yearly and according to Malaysia's Monsoon (Monthly) variation. Malaysia seasonal breakdown are as Table 1.

\begin{tabular}{|l|l|l|}
\hline Monsoon & Period & Characteristics \\
\hline Northeast & $\begin{array}{l}\text { Nov- } \\
\text { Mar }\end{array}$ & $\begin{array}{l}\text { Winds 10-20 knots upto 30 Knots during } \\
\text { cold surges period affecting east coast } \\
\text { region. } \\
\text { Heavy Rainfall }\end{array}$ \\
\hline $\begin{array}{l}\text { Inter- } \\
\text { monsoon }\end{array}$ & $\begin{array}{l}\text { Apr- } \\
\text { May } \\
\text { Oct - } \\
\text { Nov }\end{array}$ & $\begin{array}{l}\text { Frequent Period of Thunderstorm in } \\
\text { afternoon and evening hour with heavy } \\
\text { rainfall causing flash flood. }\end{array}$ \\
\hline Southwest & $\begin{array}{l}\text { May- } \\
\text { Sept }\end{array}$ & $\begin{array}{l}\text { Winds below 15 knots affecting west coast } \\
\text { region. } \\
\text { Drier weather. }\end{array}$ \\
\hline
\end{tabular}

Table 1. Monsoon regimes in Malaysia. (MMD,(Shafie, 2009)).

\section{ANALYSIS AND DISCUSSIONS}

The analyses for this study are separated into three types of series i.e. diurnally, yearly and according to monsoons. Tropical country like Malaysia received extensive variation of weather condition. Daily average will overshadow these effects as it will suppress the highest and lowest condition. This will eliminate the most remarkable and significance condition one can find. The yearly analyses show the impact of land use and land cover changes with respect to the yearly average albedo in Malaysia. While the monsoon analyses enable us to recognise the albedo behaviour and its pattern changes with respect to the local climate condition and subsequently it's dynamic towards local weather parameters. The following paragraphs will explain the results of these analyses.

\subsection{Result 1: The Time-series Analyses (Daily)}

The average daily albedo of maximum and minimum value from 2000-2009 is 0.254144 and 0.002025 respectively. Though, the highest daily albedo marked at 0.37566 at day 145 in 2005 and the lowest daily albedo value is 0.00005 at day 41 in 2004 . The variation of daily albedo in terms of its maximum value shows varies distribution over the years. As illustrated in Figure 3, there is no certain linear trend of albedo for day 1 until day 361 . It can be inferred that this values are influences by the surface properties, monsoon variation and also the diffusion of skylight. This graph is plotted using real reflectance values not the daily average values.

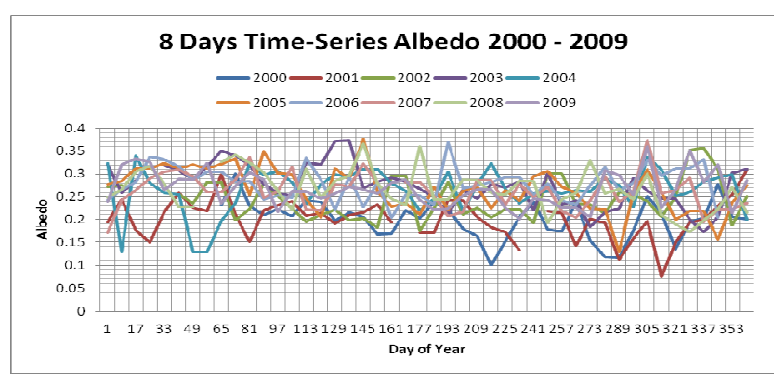

Figure 3. Daily Albedo 2000 - 2009 
However, when the each year daily linear graphs are stacked on top of each other, the trend can be clearly identified (see Figure 4). Figure 3 showed that the value of albedo for each day maybe fluctuated. However, the Figure 5 shows the pattern in which the value of albedo decreased and escalated at a consistent temporal trend and visually uniform each day for 10 years. Though, the percentage of increment maybe different which results to some spikes of rises and falls as appeared in Figure 4.

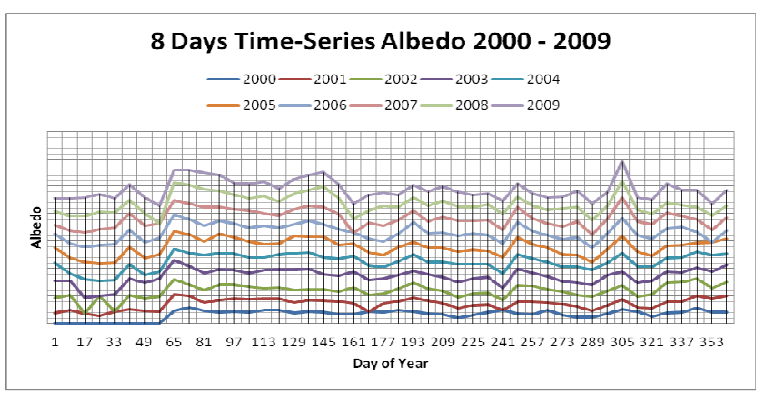

Figure 4. Daily Albedo 2000 - 2009 (stacked line)

\subsection{Result 2: The Time-series Analyses (Yearly)}

The annual average minimum and maximum albedo of Peninsular Malaysia for years 2000-2009 is 0.002016594 and 0.250059192 respectively. The temporal change trend lines of the study area present ascend trend (Figure 5). The highest albedo appears in the year 2006 and the lowest is in 2001. This change trend may be related to the land use types and the anthropogenic activities at the study area. Therefore, the companion analyses will focus on the monsoon variation.

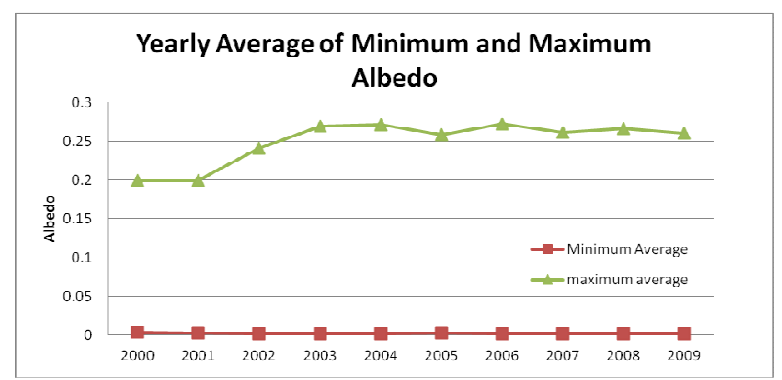

Figure 5. Yearly Minimum and Maximum Average Albedo

\subsection{Result 3: The Time-series Analyses (Monsoon)}

Northeast Monsoon (Nov-Mar) is the wet season. Southwest Monsoon (May-Sept) is the drier season and Intermonsoon tends to experience extreme weather changes and the variation is more remarkable and intense. Traditionally, higher albedo results to a colder environment, and lower albedo makes temperature increased. Monsoon time-series shows albedo were acting differently due to the influence of daylight availability. Diffusion of skylight results to some reflectance values fail to be obtained by the sensor. Thus, the refectance value and monsoon behaviour show some disagreement with the common albedo-temperature behaviour (see para. Result 4).

Figure 6 illustrates the variation of albedo in terms of the Malaysia's typical season. Day 281 until Day 329 shows some significant variation where spike can be identified and there is also an incremental movement of graph in between Day 121 to Day 145. These days are in the 2 intermediate Monsoons. Heavy rain and thunderstorm are common in these monsoons. The Southwest Monsoon represent drier season in Malaysia shows a reasonable variation (see Day 121 - 273). For year 2001 until 2005, there is a steady period, where the albedo variation is somewhat stagnant. Monsoon Time-Series Albedo $2000-2009$

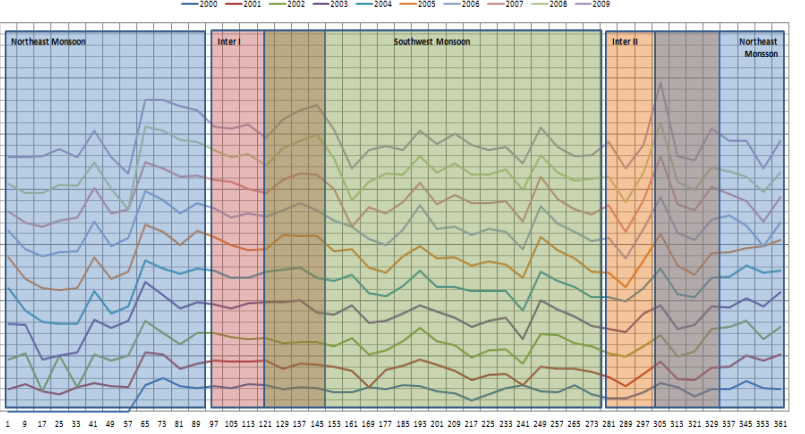

Figure 6. Monsoon Albedo Variation

However, from year 2005 to 2009, the graph shows some rapid increased of albedo (see Day 121-145). A similar pattern of rise and fall value of albedo can be seen in Day 241 to Day 249. In Northeast Monsoon (wet season) which starts from Day 305 and fall back to March at Day 89 depict some extreme rise and fall which correspond to the nature of the season where heavy rainfall, variations of windspeed and it is a cold surges period especially at the east coast region of the study area.

\subsection{Result 4: Relationship with monthly Nebulosity Index and Aerosol Optical Depth (AOD)}

The correlation analyses for the nebulosity index and the aerosol optical depth is conducted in accordance to value represented in Table 2. By selecting month (Mar, Apr, Sept and Dec) according to the highest, mean and minimum value of nebulosity index as stated in (Zain-Ahmed et al. 2002). Nebulosity index indicates the sky that is at its less diffuse situation where usually representing less cloud (less diffuse, high index). Thus, these months are chosen to look for trend of albedo over the most clear, intermediate overcast and the most diffuse sky condition in Malaysia.

\begin{tabular}{|c|c|c|}
\hline Months & $\begin{array}{c}\text { Neb } \\
\text { index }\end{array}$ & AOD \\
\hline Jan & 0.55 & 0.2 \\
\hline Feb & 0.55 & 0.25 \\
\hline Mar & 0.56 & 0.25 \\
\hline Apr & 0.58 & 0.25 \\
\hline May & 0.47 & 0.25 \\
\hline Jun & 0.55 & 0.27 \\
\hline July & 0.54 & 0.32 \\
\hline Aug & 0.54 & 0.25 \\
\hline Sept & 0.52 & 0.43 \\
\hline Oct & 0.49 & 0.5 \\
\hline Nov & 0.45 & 0.25 \\
\hline Dec & 0.43 & 0.2 \\
\hline
\end{tabular}

Table 2. Monthly Nebulosity Index (Zain-Ahmed et al. 2002) and AOD (Kanniah and Yaso 2010)

The monthly trend and the monsoon trend are influenced highly by the nebulosity index (see Figure 7). In correspondent to Figure 6, the increment and decline pattern in the graph can be conclude based on the value in Table 2. Although, December was classified as the wet and colder season, the albedo is relatively low compare to other month. This is due to the highly diffuse of skylight and being as the darkest month in a year. However, as the monsoon move to January, the albedo value is escalated as the nebulosity index is increased. Thus, Figure 7 
illustrated the correlation of albedo value with respect to the nebulosity index. It shows positive relationship as the albedo value increased as the index increased.

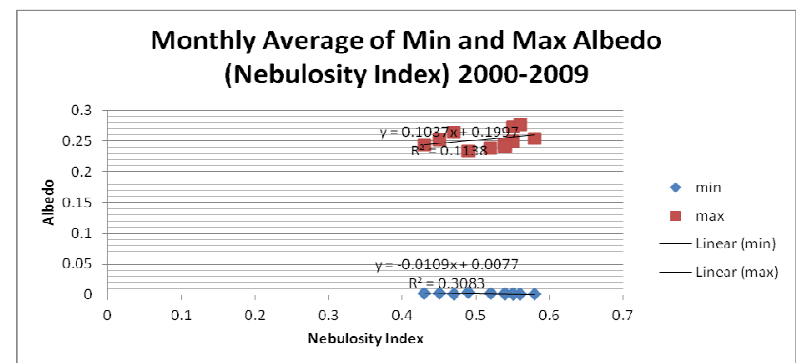

Figure 7. Nebulosity Index and Albedo Trend

In March of 2000 until 2009, the variations of albedo show minimum value of 0.00006 and maximum albedo at 0.3506 . April, on the other hands showed not much different being the same cloud condition as March, where the minimum albedo is at 0.00006 and maximum is 0.33448 . In September the albedo patterns reveals slight changes in term of its maximum value where the albedo value range from $0.00006-0.3284$ and albedo pattern is December shows the albedo value ranging from $0.001-0.35606$ for being the darkest and coldest month in the year.

The 5 years interval trend analyses results shows some contradictory behaviour of albedo with NI, thus further clarification is require verifying this condition. The following graphes show the variation of relationship of average albedo in 2000, 2005 and 2009.

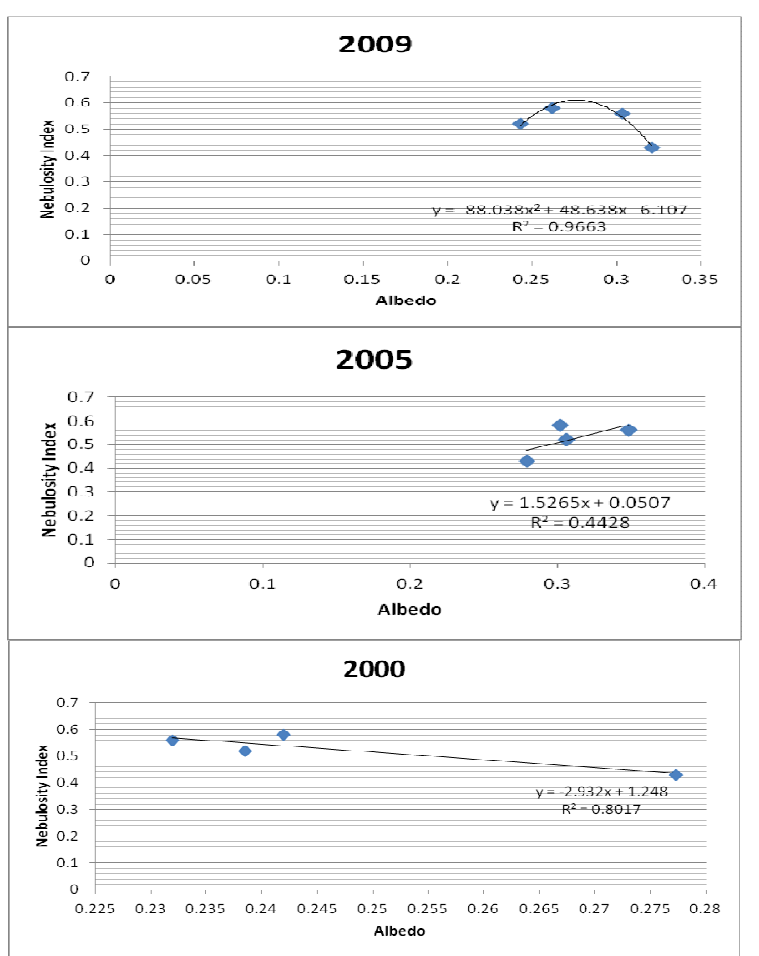

Figure 8. The 5 year Interval Average Trend Analyses

While AOD on the other hand, giving negative relationship as the AOD effects the albedo value contradictory. When the AOD is low then the albedo value is high. The linear trend can be seen in Figure 9.

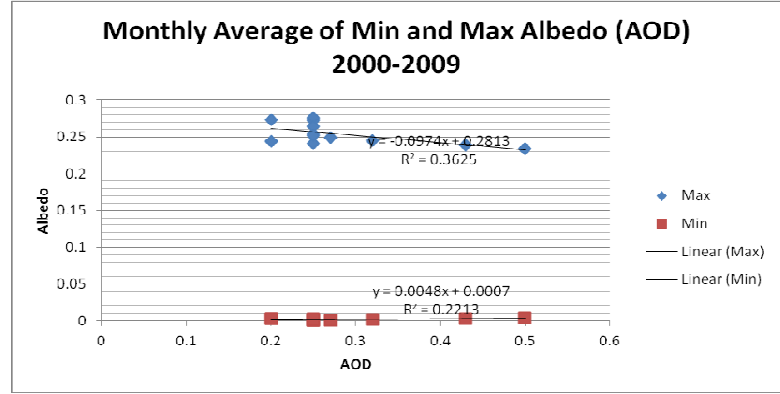

Figure 9. AOD and Albedo Trend

\section{CONCLUSION AND RECOMMENDATION}

The yearly analyses show the impact of land use and land cover changes with respect to the yearly average albedo in Malaysia. While the monsoon analyses recognized the albedo behavior and its pattern changes with respect to our local climate condition and subsequently it's dynamic towards our weather parameters. The pattern changes of albedo with respects to the nebulosity index indicate that there are external factors that implicate the albedo values. Thus, further study need to be conducted in order to gain an insight towards the relationship land surface albedo with the other variables such as property of surface reflectance (land use and land cover).

\section{ACKNOWLEDGEMENT}

The authors would like to express our gratitude to the MOSTI for funding this project under Fundamental Research Grant Scheme (FRGS) (600-RMI/SSP/FRGS/5/3Fsp (90/2010).

MODIS (MCD43A3) these data are distributed by the Land Processes Distributed Active Archive Center (LP DAAC), located at the U.S. Geological Survey (USGS) Earth Resources Observation and Science (EROS) Center (lpdaac.usgs.gov).

\section{REFERENCES}

Akbari, H., Menon, S., \& Rosenfeld, A. (2009). Global cooling: increasing world-wide urban albedos to offset $\mathrm{CO}$ 2. Climatic Change, 94, pp. 275-286.

Ambarwulan, W. (2010). PhD Thesis: Remote Sensing of Tropical Coastal Waters: Study of the Berau Estuary, East Kalimantan, Indonesia. University of Twente, ITC, Netherland.

Bala, G., Caldeira, K., Wickett, M., Phillips, T., Lobell, D., Delire, C., \& Mirin, A. (2007). Combined climate and carboncycle effects of large-scale deforestation. Proceedings of the National Academy of Sciences, 104, pp. 6550.

Cicek, I., \& Turkoglu, N. (2005). Urban effects on precipitation in Ankara. Atmosfera, 18, pp. 173-187

d'Entremont, R., Schaaf, C., Lucht, W., \& Strahler, A. (1999). Retrieval of red spectral albedo and bidirectional reflectance from 1-km2 satellite observations for the New England region. Journal of Geophysical Research, 104, pp. 6229-6339

Dixon, P., \& Mote, T. (2010). Patterns and causes of Atlanta's urban heat island-initiated precipitation, Journal of Applied Meteorology, 2, pp. 1273-1284. 
Ghazanfari, S., Naseri, M., Faridani, F., Aboutorabi, H., \& Farid, A. (2009). Evaluating the effects of UHI on climate parameters (A case study for Mashhad, Khorrasan). International Journal of Energy and Environment, 3, pp. 94101

Govaerts, Y., \& Lattanzio, A. (2008). Estimation of surface albedo increase during the eighties Sahel drought from Meteosat observations. Global and Planetary Change, 64, pp. 139-145.

Justice, C., Townshend, J., Vermote, E., Masuoka, E., Wolfe, R., Saleous, N., Roy, D., \& Morisette, J. (2002). An overview of MODIS Land data processing and product status. Remote Sensing of Environment, 83, pp. 3-15.

Kanniah, K.D., \& Yaso, N. (2010). Preliminary analysis of the spatial and temporal patterns of aerosols and their impact on climate in Malaysia using MODIS satellite data. International Archives of the Photogrammetry, Remote Sensing and Spatial Information Science, Kyoto Japan, Vol. XXXVIII, Part 8, pp. 386-391

Kiang, R., \& Ungar, S. (1977). Monitoring Earth Albedo from LANDSAT. In, LARS Symposia - Symposium on Machine Processing of Remotely Sensed Data (p. 206)

Kishtawal, C.M., Niyogi, D., Tewari, M., Pielke, R.A., \& Shepherd, J.M. (2010). Urbanization signature in the observed heavy rainfall climatology over India. International Journal of Climatology, 30, pp. 1908-1916

Kotchenova, S.Y., \& Vermote, E.F. (2007). Validation of a vector version of the $6 \mathrm{~S}$ radiative transfer code for atmospheric correction of satellite data. Part II. Homogeneous Lambertian and anisotropic surfaces. Applied optics, 46, pp. 4455-4464

Kotchenova, S.Y., Vermote, E.F., Matarrese, R., \& Klemm Jr, F.J. (2006). Validation of a vector version of the $6 \mathrm{~S}$ radiative transfer code for atmospheric correction of satellite data. Part I: Path radiance. Applied optics, 45, pp. 6762-6774

Kvalevåg, M. (2009). PhD. Thesis: Climate effects of land use changes and anthropogenic impact on surface radiation. University of Oslo, Norway.

Kvalevåg, M.M., Myhre, G., Bonan, G., \& Levis, S. (2010). Anthropogenic land cover changes in a GCM with surface albedo changes based on MODIS data. International Journal of Climatology, 30, pp. 2105-2117.

Lawrence, P.J., \& Chase, T.N. (2010). Investigating the climate impacts of global land cover change in the community climate system model. International Journal of Climatology, 30, pp. 2066-2087.

Liu, J., Schaaf, C., Strahler, A., Jiao, Z., Shuai, Y., Zhang, Q., Roman, M., Augustine, J., \& Dutton, E. (2009a). Validation of Moderate Resolution Imaging Spectroradiometer (MODIS) albedo retrieval algorithm: Dependence of albedo on solar zenith angle. J. Geophys. Res, 114

Liu, Y., Yamaguchi, Y., \& Ke, C. (2007). Reducing the discrepancy between ASTER and MODIS land surface temperature products. Sensors, 7, pp. 3043-3057
Loew, A., \& Govaerts, Y. (2010). Towards Multidecadal Consistent Meteosat Surface Albedo Time Series. Remote Sensing, 2, pp. 957-967

Lucht, W., Schaaf, C., Strahler, A., \& d'Entremont, R. (2000). Remote Sensing of Albedo Using the BRDF in Relation to Land Surface Properties. In M.M. Verstraete, M. Menenti, \& J. Peltoniemi (Eds.), Observing Land from Space: Science, Customers and Technology (pp. 175-186): Springer Netherlands

M ttus, M., \& Rautiainen, M. (2009). Direct retrieval of the shape of leaf spectral albedo from multiangular hyperspectral Earth observation data. Remote Sensing of Environment, 113, pp. 1799-1807.

Nair, U., Ray, D., Wang, J., Christopher, S., Lyons, T., Welch, R., \& Pielke Sr, R. (2007). Observational estimates of radiative forcing due to land use change in southwest Australia. $J$. Geophys. Res, 112, D09117

Nasipuri, P., Majumdar, T.J., \& Mitra, D.S. (2006). Study of high-resolution thermal inertia over western India oil fields using ASTER data. Acta Astronautica, 58, pp. 270-278

Pinty, B., Roveda, F., Verstraete, M.M., Gobron, N., Govaerts, Y., Martonchik, J.V., Diner, D.J., \& Kahn, R.A. (2000). Surface albedo retrieval from Meteosat 1. Theory. J. Geophys. Res., 105, pp. $18099-18112$

Rocchini, D. (2007). Effects of spatial and spectral resolution in estimating ecosystem [alpha]-diversity by satellite imagery. Remote Sensing of Environment, 111, pp. 423-434

Stroeve, J., Box, J.E., Gao, F., Liang, S., Nolin, A., \& Schaaf, C. (2005). Accuracy assessment of the MODIS 16-day albedo product for snow: comparisons with Greenland in situ measurements. Remote Sensing of Environment, 94, pp. 46-60 tmospheric correction of satellite data. Part I: Path radiance. Applied optics, 45, pp. 6762-6774

Vermote, E.F., El Saleous, N.Z., \& Justice, C.O. (2002). Atmospheric correction of MODIS data in the visible to middle infrared: first results. Remote Sensing of Environment, 83, pp. 97-111.

Zain-Ahmed, A., Sopian, K., Zainol Abidin, Z., \& Othman, M. (2002). The availability of daylight from tropical skies--a case study of Malaysia. Renewable energy, 25, pp. 21-30.

Zhao, W., Tamura, M., \& Takahashi, H. (2001). Atmospheric and spectral corrections for estimating surface albedo from satellite data using 6S code. Remote Sensing of Environment, 76, pp. 202-212.

Zhou, L., Dickinson, R., Ogawa, K., Tian, Y., Jin, M., Schmugge, T., \& Tsvetsinskaya, E. (2003). Relations between albedos and emissivities from MODIS and ASTER data over North African Desert. Geophys. Res. Lett, 30, pp. 2026 